7 Kline L, Margulies SL, Oh SJ. Optic neuritis and myelitis following rubella vaccination. Arch myelitis following rubel

8 Riikonen $R$. The role of infection and vaccination in the genesis of optic neuritis and multiple sclerosis in children. Acta Neurol Scand 1989;80: 425-31.

9 Kriss A, Francis DA, Cuendet F, Halliday AM, Taylor DSI, Wilson J, et al. Recovery after optic neuritis in children. $\mathcal{F}$ Neurol Neurosurg Psychiatry 1988;51:1253-8.

10 Parkin PJ, Hierons R, McDonald WI. Bilateral optic neuritis. A long term follow up. Brain 1984;107:951-64.

11 Riordan-Eva P, Sanders MD, Govan GG, Sweeney MG, Da Costa J, Harding AE. The clinical features of Leber's hereditary optic neuropathy defined by the presence of a pathogenic 2):319-37.

12 Stratton KR, Howe CJ, Johnston Jr RB. Adverse events associated with childhood vaccines. Evidence bearing on causality. Vaccine safety committee. Washington DC: Institute of Medicine, National Academy Press, 1994.

\section{Retinal arterial occlusion associated with resistance to activated protein $C$}

EDITOR,-Resistance to activated protein C (APC) was described in 1994 as a thrombophilic factor responsible for deep venous thrombosis and pulmonary embolism. ${ }^{12}$ It represents the major cause of thrombophilic disorder in the normal population (5\%). APC is an important component of the physiological anticoagulant system that inhibits factors $\mathrm{Va}$ and VIIIa. The resistance to APC is related to a single mutation in the factor $\mathrm{V}$ gene which causes the switch from arginine to glutamine at position 506. This mutation of factor $\mathrm{V}$ blocks the site of cleavage by APC. ${ }^{3}$ Reported thrombophilic manifestations include venous thrombosis and a case of central retinal vein thrombosis. ${ }^{4}$ Arterial occlusion is not clearly associated with resistance to APC. Ischaemic stroke was recently reported in three patients with resistance to APC. ${ }^{5}$ We described a case of branched retinal artery occlusion associated with resistance to APC.

\section{CASE REPORT}

A 35-year-old non-smoking man was referred for a sudden decrease of visual acuity in the left eye. He had no familial or personal history of thrombophilic disorders. At examination, his best corrected visual acuity was $20 / 20$ in the right eye and $20 / 30$ in the left. A superotemporal branched retinal artery occlusion was noted in the left eye with an oedematous, whitish, retinal infarction in the affected vessel. A fluorescein angiogram confirmed the branched retinal artery occlusion (Fig 1). After 2 months, visual acuity improved to $20 / 25$ in the left eye. He had a permanent visual field defect in the area of damaged retina confirmed by Goldmann perimetry. Cardiac rhythm was regular; transthoracic echocardiography, and carotid Doppler studies showed no abnormalities. Red blood cell, white cell, platelet counts, and erythrocyte sedimentation rate were all normal. Platelet aggregation was normal. A search for antinuclear and anticardiolipin antibodies was negative. Prothrombin time and activated partial thromboplastin time (APTT) were normal. Plasma levels of protein $C, S$, antithrombin III, fibrinogen, plasminogen, plasminogen activator inhibitor were within normal ranges. APC resistance was determined by evaluating the anticoagulant response of plasma samples to APC with an APTT based assay. Results were expressed as the following APC sensitivity ratio (APTT + APC)/(APTT - APC). The cut off value was 2.2. In our patient, the APC

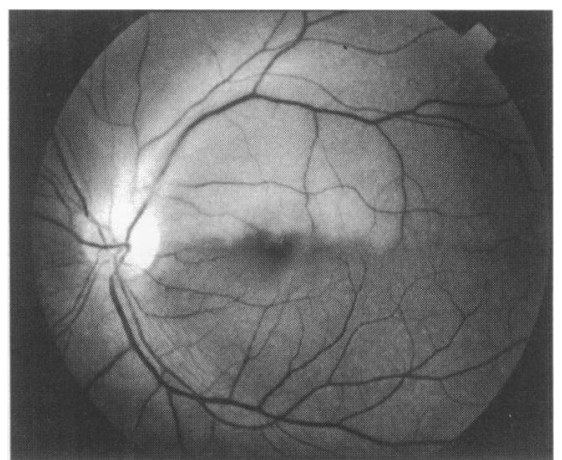

Figure 1 Superotemporal branched retinal artery occlusion.

sensitivity ratio was 2.1. Heterozygous factor V Leiden mutation was disclosed by molecular analysis.

\section{COMMENT}

Occlusion of the retinal artery is more rarely encountered in younger than in older patients. ${ }^{6}$ Multiple causes of arterial occlusion in the retina were described. In a recent report, the causes of retinal arterial occlusions in 21 young adults were analysed. ${ }^{7}$ Emboli were identified in $33 \%$ of the patients. Cardiac valvular disease, including atrial myxoma, bacterial endocarditis, and mitral valve vegetation due to lupus anticoagulant, was the mainly recognised condition and was present in $19 \%$ of the patients. Other associated risk factors for cerebrovascular occlusion such as cigarette smoking, oral contraceptive use, obesity, pregnancy, and Behçet's disease were found in $91 \%$ of the patients. Antithrombin III, protein $\mathrm{S}$, or protein $\mathrm{C}$ deficiencies are hypercoagulable conditions that can lead to recurrent venous or arterial thrombotic events. ${ }^{8}$ Protein $S$ deficiency was associated with a case of bilateral branch retinal artery occlusion. ${ }^{9}$ This biological abnormality was detected in only one young woman with diabetes mellitus and pregnancy in the series of Greven et al. ${ }^{7}$ Antiphospholipid antibody syndromes are thrombophilic factors that occur in patients with either lupus anticoagulants or antibodies to anticardiolipin or dissociated syphilis serology. Antiphospholipid antibodies can lead to recurrent arterial and/or venous thrombosis. ${ }^{10}$

APC resistance is clearly related to venous thromboembolism. ${ }^{2}$ A recent report suggests the possible role of APC resistance in arterial thrombosis. ${ }^{5}$ APC resistance was not searched for as a thrombophilic factor in retinal arterial occlusions in young adults. In our case, the cause of retinal arterial occlusion could be attributed to the heterozygous mutation of factor V. Owing to the severity of retinal arterial occlusion, long term oral anticoagulant treatment was proposed in our patient for secondary prevention of thrombosis. APC resistance should be considered in patients with retinal arterial occlusion when the usual embolic or thrombotic diseases are ruled out.

STÉPHANE VIGNES BERTRAND WECHSLER Service de Médecine Interne, Hôpital de la Pitié-Salpétrière,

47-83 Boulevard de l'Hôpital, 75651 Paris Cedex 13

CLAUDE ELMALEH

Service d'Ophtalmologie, Hôpital Hôtel-Dieu, 1 place du Parvis de Notre Dame, 75181 Paris Cedex 04

NATHALIE CASSOUX Service d'Ophtalmologie, Hoppital de la Pitiè-Salpétrière, 47-83 Boulevard de l'Hôpital, 75651 Paris Cedex 13
MARIE HÉLÈNE HORELLOU Laboratoire Central d'Hématologie, Hôpital Hôtel-Dieu,

1 Place du Parvis de Notre Dame, 75181 Paris Cedex 04 PIERRE GODEAU

Service de Médecine Interne,

Hôpital de la Pitié-Salpétrière, 47-83 Boulevard de l'Hôpital, 75651 Paris Cedex 13 Correspondence to: B Wechsler, Service de Médecine Interne, Hôpital de la Pitié-Salpétrière, 47-83 Boulevard de l'Hôpital, 75651 Paris Cedex 13, France.

Accepted for publication 13 September 1996

1 Dahlbäck B. Physiological anticoagulation: resistance to activated protein $C$ and venous
thromboembolism. $\mathcal{f}$ Clin Invest 1994;94:923-7. 2 Svensson PJ, Dahlbäck B. Resistance to activated Svensson PJ, Dahlbäck B. Resistance to activated
protein $\mathrm{C}$ as basis for venous thrombosis. $N$ Engl $\Im$ Med 1994;330:517-22.

3 Zöller B, Dahlbäck B. Linkage between inherited resistance to activated protein $C$ and factor $V$ mutation in venous thrombosis. Lancet 1994; 343:1536-83.

4 Dhôte R, Bachmeyer C, Horellou $\mathrm{MH}$, Toulon $\mathrm{P}$, Christoforov B. Central retinal vein thrombosis associated with resistance to activated protein associated with resistance to activated
C. Am $\mathcal{f}$ Ophthalmol 1995;120:388-9.

5 Simioni P, de Ronde H, Prandoni P, Saladini M, Simioni P, de Ronde H, Prandoni P, Saladini M,
Bertina RM, Girolami A. Ischemic stroke in young patients with activated protein $C$ resistance. Stroke 1995;26:885-90.

6 Brown GC, Magargal LE, Shields JA, Goldberg RE, Walsh PN. Retinal arterial obstruction in children and young adults. Ophthalmology 1981; 88:18-25.

7 Greven CM, Slusher MM, Weaver RG. Retinal arterial occlusions in young adults. $A m \mathcal{F}$ Ophthalmol 1995;120:776-83.

8 Israel SJ, Seshia SS. Childhood stroke associated with protein $\mathrm{C}$ or $\mathrm{S}$ deficiency. $\boldsymbol{f}$ Pediatr 1987;111:562-4.

9 Greven CM, Weaver RG, Owen J, Slusher MM. Protein $S$ deficiency and bilateral branch retinal artery occlusion. Ophthalmology 1991;98:33-4.

10 Love PE, Santoro SA. Antiphospholipid antibodies: anticardiolipin and the lupus anticoagulant in systemic lupus erythematosus (SLE) and in non-SLE disorders. Prevalence and clinical significance. Ann Intern Med 1990;112:68298.

Recurrent septic retinal emboli following dental surgery

EDrToR,-Metastatic bacterial endophthalmitis following head and neck surgery is rare. ${ }^{1-3}$ To our knowledge, no case of recurrent septic retinal emboli with a presumed dental source has been described before.

\section{CASE REPORT}

A healthy 36-year-old white man presented to a dental surgeon with a localised periapical abscess at his right upper first molar, which was confirmed by dental $x$ ray. A volume of $0.2 \mathrm{ml}$ of pus was drained after local periapical infiltration with $2 \%$ lignocaine $1 \mathrm{ml}$ with adrenaline 1:80 000 and postoperative irrigation with $0.01 \%$ dexamethasone solution. $\mathrm{He}$ was prescribed oral amoxycillin/clavulanic acid $375 \mathrm{mg}$ three times daily but did not start antibiotics until 12 hours after the procedure. Three days later, the patient noted sudden blurring of vision and floaters in his right eye but was systemically well.

There was no previous ocular history and the medical history was negative for intravenous drug use, rheumatic fever, or other cardiac disease. He had no risk factors to suggest systemic immunosuppression. General examination was unremarkable and, significantly, he was afebrile with no cardiac signs or peripheral stigmata of infective endocarditis. Uncorrected visual acuity was $6 / 5$ in both eyes and there was no relative afferent 
pupillary defect. Anterior segment examination was normal. Funduscopy revealed multiple white emboli in branches of the right inferotemporal retinal artery with superficial retinal haemorrhage and macular oedema (Fig 1). There were also smaller emboli in the left inferonasal, inferotemporal, and superonasal retinal arteries (Fig 2). Vitreous cells 1+ were noted in both eyes. This appearance was consistent with bilateral septic retinal emboli.

Fluorescein angiography showed hypofluorescence at and distal to the right intra-arterial emboli with normal choroidal fluorescence and a normal angiogram appearance in the left eye. The white blood cell count was 10.3 with a normal differential and his erythrocyte sedimentation rate was $2 \mathrm{~mm}$ in the first hour Serial blood cultures produced no growth and a gingival swab produced normal flora.

Electrocardiography, transthoracic echocardiography, and a carotid duplex scan were normal. Fasting total cholesterol and triglycerides were mildly elevated at 6.1 and 2.89 $\mathrm{mmol} / \mathrm{l}$ (upper limits of normal 5.8 and 1.8 $\mathrm{mmol} / \mathrm{l})$ respectively. Coagulation studies and plasma viscosity were normal. Values for antinuclear antibody, anticardiolipin antibodies, activated protein $\mathrm{C}$ resistance, antithrombin III, protein $\mathrm{C}$, and protein $\mathrm{S}$ were all normal. No other infective source was found and $h$ was started empirically on cefuroxime $750 \mathrm{mg}$ intravenously three times daily, metronidazole $500 \mathrm{mg}$ intravenously three times daily, hydrocortisone $100 \mathrm{mg}$ intravenously four times daily, and aspirin $300 \mathrm{mg}$ orally daily. There was little change in the fundal appearance over the next few days but visual acuity remained good at $6 / 5$ in both eyes.

On discharge, on the fourth day, he was converted to oral antibiotics and steroids for a further 2 weeks. At a 1 week follow up visit there was reduced vitreous activity which

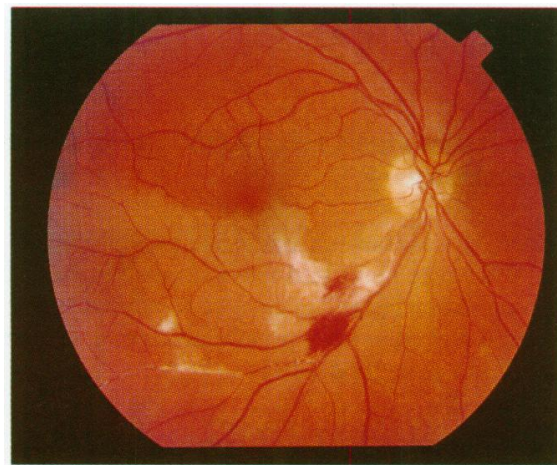

Figure 1 White emboli in branches of the right inferotemporal retinal artery with macular oedema and superficial retinal haemorrhage at first presentation.

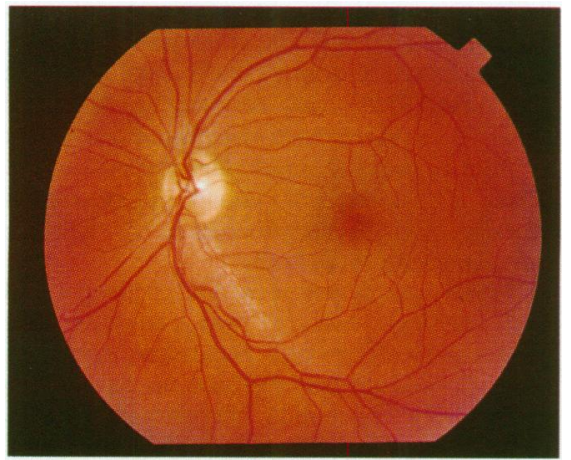

Figure 2 Close inspection revealed small white emboli in branches of the left inferonasal, inferotemporal, and superonasal retinal arteries at initial presentation. resolved at 2 weeks and the emboli appeared a little smaller. Two months later, he underwent extraction of his previously abscessed tooth under periapical local anaesthetic having started oral amoxycillin/clavulanic acid and metronidazole 3 days earlier for 1 week.

Three weeks afterwards, he presented with fresh bilateral white intra-arterial septic retinal emboli and bilateral vitreous cells $2+$. Blood cultures were negative and there was no clinical evidence of infective endocarditis. Repeat haematological investigations were normal. CD4 count was normal and cytomegalovirus titres were negative. His symptoms settled and the emboli reduced in size after 5 days of cefuroxime $750 \mathrm{mg}$ intravenously three times daily and metronidazole $500 \mathrm{mg}$ intravenously three times daily, which was continued orally for a further 2 weeks. Oral aspirin therapy was commenced. He presented 1 month later while on aspirin, with renewed vitreous activity and right inferotemporal and superotemporal retinal arterial emboli. He was given intravenous cefuroxime and metronidazole for 7 days converting to oral therapy for a further 2 weeks. Oral anticoagulants were started and he had no further episodes. Seven month later, visual acuity remains at $6 / 5$ in both eyes but small white intra-arterial emboli persist with distal luminal narrowing and pallor.

\section{COMMENT}

Focal metastatic endophthalmitis with discrete retinal septic emboli is a very rare complication of dental surgery. ${ }^{12}$ The clinical appearance in this patient and subsequent partial resolution following intravenous antibiotics implicate infective emboli. The dental origin of sepsis in this patient was presumed as each episode occurred within 1,3 , and 7 weeks of dental surgery on an infected tooth and no other focus was found. The initial episode may have been due to an initial transien bacteraemia or possibly paradoxical embolism but the subsequent delayed episodes may have been of cardiac origin. A normal transthoracic echocardiogram cannot completely rule out the possibility of an intracardiac communication allowing right to left shunting and paradoxical embolism. ${ }^{4}$

The third episode of acute septic emboli occurred 7 weeks after dental extraction and may be due to subclinical infective endocarditis despite negative investigations. Each episode was treated with 1 week or less of intravenous antibiotics which may have been insufficient. Transient bacteraemia following dental surgery has been reported to occur in $15-55 \%$ of cases, ${ }^{5}$ the most common organism being viridans streptococci. ${ }^{6}$ Amoxycillin is regarded as the most appropriate antibiotic prophylaxis for patients at risk for infective endocarditis after dental surgery. ${ }^{7}$ However prophylactic administration of amoxycillin does not reduce the incidence of postextraction bacteraemia ${ }^{8}$ and may not affect bacteria cardiac adherence.

Despite amoxycillin prophylaxis in this otherwise healthy patient, septic retinal emboli developed 3 weeks after the dental procedure. Focal metastatic endophthalmitis, if treated with appropriate antibiotics, has an excellen prognosis with minor permanent ocular changes. ${ }^{9}$ Our patient maintained an excellen visual acuity of $6 / 5$ in both eyes but scotomat persisted corresponding to ischaemic retin distal to the arterial emboli despite appropriate antibiotic therapy. Despite the lack of supporting evidence, the possibility of subclinica infective endocarditis cannot be excluded to account for recurrent septic retinal emboli following dental surgery in this patient.

D J KILMARTIN

P BARRY

Research Foundation, Royal Victoria Eye and Ear

Hospital, Dublin, Ireland

Correspondence to: Mr D J Kilmartin, Department of Ophthalmology, Aberdeen Royal Infirmary, Foresterhill, Aberdeen AB9 2ZD.

Accepted for publication 27 August 1996

1 May DR, Peyman GA, Raichand M, Friedman E. Metastatic endophthalmitis after a dental procedure. Am ₹ Ophthalmol 1978;85:662-5.

2 King LP, Libby C, Coats DK, Lee WH 3d. Presumed septic emboli following dental extraction. Graefes Arch Clin Exp Ophthalmol 1993; 231:667-8.

3 Weinberg RS, Dorfman MS. Vitritis as the initial presentation of bacterial endocarditis. In: Dernouchamps JP, Verougstraete C, Caspers-Velu $\mathrm{L}$, Tassignon MJ, eds. Recent advances in uveitis. Amsterdam: Kugler Publications, 1993:29-30.

4 Konstadt SN, Louie EK. Echocardiographic diagnosis of paradoxical embolism and the potential for right to left shunting. Am f Cardiac Imaging 1994;8:28-38.

5 Bayliss R, Clarke C, Oakley C, Sommerville W, Whitfield AG. The teeth and endocarditis. $\mathrm{Br}$ Heart f 1983;50:506-12.

$6 \mathrm{Knox} \mathrm{KW,} \mathrm{Hunter} \mathrm{N.} \mathrm{The} \mathrm{role} \mathrm{of} \mathrm{oral} \mathrm{bacteria} \mathrm{in}$ the pathogenesis of infective endocarditis. Aust Dent F 1991;36:286-92.

7 Leport C, Horstkotte D, Burckhardt D. Antibiotic prophylaxis for infective endocarditis from an international group of experts towards a from an internation a European consensus. Group of Experts of the International Society for Chemotherapy. Eur Heart ₹ 1995;16 (Suppl B): 126-31.

8 Hall G, Hedstrom SA, Heimdahl A, Nord CE. Prophylactic administration of penicillins for endocarditis does not reduce the incidence of postextraction bacteremia. Clin Infect Dis 1993; 17:188-94

9 Greenwald MJ, Whol LG, Sell CH. Metastatic bacterial endophthalmitis: a contemporary appraisal. Surv Ophthalmol 1986;31:81-101.

\section{An unusual corneal injury}

EDrToR,-Most thermal injuries to the cornea are superficial and tend to heal rapidly ${ }^{12}$ but deeper sight threatening burns may occur when extended contact between the heat source and the cornea occurs. ${ }^{3}$ New methods of demolition using an exothermic chemical reaction to crack stone and reinforced concrete are becoming increasingly popular. We present a man who sustained severe bilateral thermal corneal burns following exposure to such a chemical.

\section{CASE PRESENTATION}

Mr JP presented with bilateral corneal injuries and hand movement vision in both eyes. One hour earlier a tube of 'Betonamit' had exploded into his face.

Betonamit, a 'non-explosive' cracking agent is a mixture of calcium oxide, silicon oxide, aluminium oxide, and magnesium oxide, which when hydrated forms calcium hydroxide in an exothermic reaction. During normal use it is mixed with water and poured into drill holes of specific depth and diameter. The substance then expands and pressures of up to 9000 tonnes $/ \mathrm{m}^{2}$ develop, fracturing the surrounding concrete/stone.

The patient had dense white corneal opacities in both eyes with lacunae of transparent healthy cornea (Fig 1). Similarly, there were multiple patches of pale conjunctiva. The face and lids were unharmed. He immediately underwent ocular irrigation and particulate material was removed from the fornices. The pH was not lowered; nevertheless, the initial clinical impression was of severe bilateral 